\title{
IMMUNE RESPONSE OF STIMULATED BIOMPHALARIA ALEXANDRINA SNAILS WITH SCHISTOSOMA MANSONI INFECTION
}

\author{
By \\ SAMAH I. GHONAME ${ }^{1}$, AMIRA H. MOHAMED ${ }^{2}$ and SHADIA M. EL- DAFRAWY ${ }^{3^{\star}}$ \\ Department of Medical Malacology ${ }^{1,3}$ and Electron Microscopy ${ }^{2}$, Theodor Bilharz \\ Research Institute, P.O. Box 30, Imbaba, Giza, Egypt \\ ( ${ }^{\star}$ Correspondence:shadia2004@hotmail.com)
}

\begin{abstract}
In this study, both digestive and hermaphrodite glands in Biomphalaria alexandrina snails were examined by light microscope (LM) and scanning electron microscopy (SEM) in a trial to clarify its immunological role as defense mechanism against the parasite infection. B. alexandrina snails used were exposed individually to Schistosoma mansoni miracidia; according to their response they were classified into infected snails (shed cercariae) and non-infected snails (failed to shed cercariae). Snails not exposed to $S$. mansoni miracidia used as control. LM showing great histological alteration in tissues of the both glands in infected snails, these changes represented by degenerated both oocyte and spermatocyte in hermaphrodite gland in addition to degenerated digestive gland while non-infected snails showing mild degenerated ova with normal spermatocytes also degenerated miracidia inside granuloma like structure with concentric layers of fibroblast and haemocyte could be observed. By SEM we could detect extensively damaged and fibrosed non-motile cilia with exfoliation of tegumental surface in infected B.alexandrina while non-infected ones showing attached numerous cilia with some ballooning of the folds.
\end{abstract}

Key words: Immune response; Biomphalaria alexandrina; Light and scanning electron microscopy.

\section{Introduction}

Schistosomiasis is one of the most significant neglected tropical diseases affecting about 239 million people (WHO, 2012). The internal defense system (IDS) of snails is composed of cellular elements; haemocytes and soluble factors present in haemolymph. They play an important role in the innate immune responses of mollusks and have important factors in fighting snail infections (Farahnak et al, 2005). Haemocytes play the prominent role in parasite and pathogen elimination and may be circulating in haemlymph or fixed in tissues. Snail haemocytes are able to the mount a cytotoxic response against parasites (Bahgat et al, 2002). IDS is one of the factors that influence the susceptibility pattern of the snails. This system is stimulated by the excretory secretory products (ESPs) of the penetrating miracidia (Zahoor et al, 2010). Parasites face many challenges such as gaining enough energy to grow and to evade the host defense system (Meuleman et al, 1987; DeJong-Brink et al, 2001).
Infection of snails with schistosomes involves two operations, namely the miracidal penetration into the snail and subsequent development of the parasite inside the snail body till production of cercariae. The hostparasite relationship is complex and questions remain concerning the susceptibility of snails to infection by the respective trematodes and their suitability as hosts for continued parasite development. B. alexandrina, the intermediate hosts of intestinal schistosomiasis may be either susceptible or resistant to infection by $S$. mansoni (Sasaki et $a l, 2003)$. Resistance can take several forms either parasite was not attracted to the snail, could not penetrate it, the penetrated snail degenerated immediately or after some development or actively destroyed by the snail defense system after penetration (Rizk et al, 2011).

The digestive gland of mollusks is involved in the extracellular and intracellular digestion absorbed of food material absorption of nutrients, storage of lipids, glycogen and minerals, in addition to its major role in de- 
toxification (Henry et al, 1989). Abdel Hamid et al. (2007) showed harmful degeneration and great damage in the cells of the hermaphrodite gland in infected $B$. alexandrina that affecting reproduction by destroying gametocytes and increasing snail mortality.

The present work was designed to study the immune response of infected B. alexandrina snails with $S$. mansoni miracidia by light and scanning electron microscope.

\section{Materials and Methods}

Biomphalaria alexandrina snails were obtained from the laboratory-bred stock in Medical Malacology (TBRI) Egypt. B. alexandrina snails were exposed individually to ten $S$. mansoni miracidia in the presence of 2 $\mathrm{ml}$ of dechlorinated aerated tap water under florescent light at temperature $\left(25 \pm 1^{\circ} \mathrm{C}\right)$. They remained in contact with miracidia overnight and then transferred to the original aquaria at $25 \pm 1^{\circ} \mathrm{C}$ throughout the infection process. The fresh lettuce leaves were supplied as food every couple of days and the dead snails were regularly removed. Thirty days post infection; the snails were checked individually for the cercarial shedding (Kamel et al, 2006; Helal et al, 2014a,b).

Two groups (each group of 120 snails) were used, as follows: group (G1) snails nonexposed to $S$. mansoni miracidia used as control. Group (G2) snails exposed to $S$. mansoni miracidia, this group include infected snails (that shed cercariae) and noninfected ones (that failed to shed cercariae). 36 snails were used from each control, infected and non-infected snails for examination under light and scanning electron microscopy.

Histological methods by light microscope: Each group was carefully crushed between two glass-slides, the shell fragments were removed under a dissecting microscope. Soft tissues were separated and immediately fixed in alcoholic Bouin's fluid ( $15 \mathrm{ml}$ picric acid (saturated aqueous solution), $5 \mathrm{ml}$ of $40 \%$ formalin, and $1 \mathrm{ml}$ of $100 \%$ glacial acetic acid) for 12 hours. After fixation, specimens were dehydrated in an ascending series of alcohol $(70 \%, 80 \%, 90 \% \& 100 \%)$ each 15 minutes. The specimens were cleared in two changes of xylene and embedded in molten paraplast at $60^{\circ} \mathrm{C}$. The serial sections were cut at $5 \mu$ thickness using rotary microtome and stained with Ehrlich's haematoxylin and counterstained eosin (Romeis, 1989). The sections were then mounted by DPX and covered by glass cover histological sections were examined and photographed with automatic camera using Olympus System Microscope.

Scanning electron microscope: The tissues were fixed in equal volumes of glutaraldehyde $4 \%+$ Cacodylate $0.2 \%$ for 2 hours. It was then washed in equal volumes of $\mathrm{Su}$ crose $0.4 \%$ and Cacodylate $0.2 \%$ for 2 hours, Post fixed in equal volumes of osmic acid $2 \%$ and Cacodylate $0.3 \%$ for an hour, washed with distilled water. Finally dehydrated in ascending grades of ethanol for 5 min each $(30 \%, 50 \%, 70 \%$ and 90\%) then absolute alcohol $100 \%$ for 10 min for 3 times. Samples were immediately processed (Glauert, 1974).

Statistical analysis: Data were analyzed by Statistical package for Social Sciences for Windows version 22.0 (SPSS, Chicago, IL, USA). Descriptive statistics for each variable was determined. Results for continuous variables were demonstrated as data were expressed as test of proportion. $P$-values of less than 0.05 were considered significant

\section{Results}

The results are given (Tab. 1)

Table 1: Effect of infection with Schistosoma mansoni in survival rate and percentage infection in Biomphalaria alexandrina.

\begin{tabular}{|l|c|c|c|c|c|c|}
\hline \multirow{2}{*}{ Groups } & \multicolumn{2}{|c|}{ Surviving } & $\begin{array}{c}\text { Infected snails, } \\
\text { shed cercariae }\end{array}$ & $\begin{array}{c}\% \\
\text { Infected }\end{array}$ & $\begin{array}{c}\text { Non-infected snails, not } \\
\text { shed cercariae }\end{array}$ & $\begin{array}{c}\% \\
\text { Non infected }\end{array}$ \\
\cline { 2 - 7 } & No. & $\%$ & & & & \\
\hline Control group (G1) & 104 & 86.8 & & & $36 / 92$ & 39.1 \\
\hline Exposed to miracidia (G2) & 92 & $76.7 *$ & $56 / 92$ & $60.9 * * \#$ & $36 / \%$ \\
\hline
\end{tabular}

Number of snails used in each group $120 .{ }^{*} p<0.05$ significant decrease than control, ${ }^{* *} p<0.01$ highly significant decrease than control, ${ }^{\#}<0.01$ highly significant increase than non -infected. 
The survival rate of $B$. alexandrina in control group (G1) was $86.8 \%$ while in exposed snails to miracidia (G2) was $76.7 \%$ with significant difference than control $(p<0$. $05)$. The majority of exposed snails to miracidia were infected $(60.9 \%)$, while $39.1 \%$ were non-infected. There was highly significant decrease between infected snails than control $(\mathrm{P}<0.01)$ and highly significant increased between infected snails than noninfected snails $(p<0.01)$.

Histopathological examinations: Light microscope, examination of control group (G1) B. alexandrina tissue showed normal histology of digestive gland (endothelial cell, lumen, Basment Membrane) (Fig. 1A), developmental stages of spermatocyts and oocyte (Fig.1B).

Exposed snails to miracidia (G2): Infected snails showed degenerated digestive gland, oocyte and spermatocyte (Fig.1 C, D, \& E). Non infected snails showed: mild degenerated ova with normal spermatocytes (Fig.1F), degenerated miracidia inside granuloma like structure with concentric layer of fibroblast and haemocyte (Fig. 1G), folded miracidia entrapped within snail hermaphrodite gland surrounded by haemocyte (Fig. 1H) and granuloma-like structure in digestive gland (Fig. 1I).

Scanning Electron Microscope: In control group (G1) showed densely attached numerous cilia (Fig. 2A). High magnification showed many folds and cilia (Fig.2B), smooth tegumental surface of mental visceral mass (Fig. 2C). Exposed snails to miracidia (G2).Infected snails showed extensively damaged and fibrosed non-motile cilia (Fig. 2D \& E), exfoliation of tegumental surface with appearance of sub-tegumental tissue (Fig. 2F). Non-infected snails showed attached numerous cilia (Fig. 2G).High magnification showed some ballooning of the folds (Fig. 2H \& I).

\section{Discussion}

Many studies investigated the mechanisms by which the snail resistance was achieved
(Granath and Yashino, 1983; Loker and Bayne, 1986). Dynamic interaction between the molluscs and their trematode parasites led either to a state of co-existence, in which the trematode thrives and produces subsequent stages of its life-cycle, or to incompatibility, where the trematode is either destroyed and eliminated by the host snail defensive responses or fails to develop because the host is physiologically unsuitable (Mohamed et al, 2011).

Susceptibility generally is viewed to be the result of hemocytes failure to recognize and/or mount an effective cytotoxic response against the invasive parasite larvae. Mohamed et al. (1993) reported that the interaction between $S$. mansoni and the internal defense system of the snail is the main effecter element in the destruction of the parasite. Parasites need to penetrate into this host, develop multiply asexually and finally leave the host to continue their life cycle (Davies and Mckerrow, 2003; Parker et al, 2003).

In the present study, $B$. alexandrina exposed to $S$. mansoni miracidia showed increase the mortality rate than control. This agreed with several authors who observed that larval trematode infections frequently affected survivorship and fecundity of the snail hosts (El-Sayed et al, 1999; El-Dafrawy et al, 2001).

De Jong-Brink et al. (1988) suggested that the parasite produces a factor that interferes with the activity of the reproductive hormones. Also, Holmes and Zohar (1990) found that the most direct action occurred when a parasite localized in an organ and interfered with the function of that organ mechanically or through destruction of its tissue. Thompson (1993) also reported that infected snails with schistosomes showed a dramatic reduction in the snail's ability to produce eggs or complete cessation of egg production which may be due to energy depletion or may be resulted from direct nutritional deprivation. Also, Bakry (2009) and Sullivan and Yeung (2011) found histologi- 
cal damage and evacuation in digestive gland \& gametogenic stages of infected snails.

These findings were in a harmony with the histological results of infected $B$. alexandrina which showed sever histopathological changes of hermaphrodite gland represented by degeneration, vaculation and deformation of oocyte and spermatocyte in addition to sever digestive gland degeneration.

Granuloma like structures in the present results were seen 30 days postmiracidial exposure represented by a number of up to four layers of accumulating hemocytes surrounded the miracidia. These multiple layers of hemocytes act as a wall that isolates them preventing the uptake of nutrients present in the hemolymph of the snails. Such haemocytes responses were reported especially in snails resistant to dignean trematodes (Lemos and Andrade, 2001). Helal et al. (2014a) found that the haemocytes are directly involved in the death of some encapsulated parasites. The study went on with the present histological result of non-infected group that showed mild degenerated ova with normal spermatocytes, degenerated miracidia inside granuloma like structure of concentric layer of fibroblast, haemocyte and folded miracidia entrapped within hermaphrodite gland surrounded by haemocyte. Also, the results agreed with Mohamed et al. (2011) who found that although the miracidia of the parasite successfully penetrate the snail, they are quickly subjected to strong tissue reactions leading into the encapsulation of the parasite larvae followed by degeneration and eventual exclusion from the resistant snails' tissues where hemocytes could recognize and destroy parasite by a cellular encapsulation response that may involve plasma activating or recognition factors, lysosomal enzymes or other cytotoxic elements and phagocytosis of the damaged parasite tegument.

The results were confirmed by SEM, which showed attached numerous cilia at the ventral surface with only some ballooning of the folds in non-infected snails, while extensivly damaged and fibrosed non motile cilia, exfoliation of tegumental surface and appearance of sub-tegumental tissue in infected group could be observed which agreed with ElBeshbishia et al. (2015) who found mark-ed distortion of the tentacle with exfoliation and erosion with exposure of subtegumental tissue in infected snails

\section{Conclusions}

The outcome results clarified the link between snail immunity and its susceptibility to increase snail immunity and played a role in host protection against parasites and limit the spread of the pathogen and subsequently control parasites transmitted by host snails.

\section{Acknowledgment}

The authors would like to thank Dr. Hoda Abu-Taleb, Biostatistics and Demography, Environment Research Department, Theodor Bilharz Research Institute for her kind help in the statistical analysis.

\section{References}

Abdel Hamid H, El-Housseny A, Tantawy A, El-Dafrawy S, 2007: Histological studies on the consequence antagonism of Echinostoma liei to Shistosoma mansoni in Biomphalaria alexandrina snails. Egypt. J. Exp. (Zool).3:145-50.

Bahgat, M, Doenhoff M, Kirschfink, M, Ruppel, A, 2002: Serine protease and phenoloxidase activities in haemocytes of Biomphalaria glabrata snails with varying susceptibility to infection with the parasite Shistosoma mansoni Parasit. Res. 88:489-94.

Bakry, FA, 2009: Effect of Infection with Shistosoma mansoni on some biological parameters in Biomphalaria alexandrina snails. American Eurasian J. Sci. Res. 4:180-90.

Davies, SJ, Mckerrow, JH, 2003: Developmental plasticity in schistosomes and other helminths. Int. J. Parasitol. 33:1277-84.

De Jong-Brink, M, Elsaadany, MM, Boer, H H, 1988: Trichobilharzia ocellata: Interference with endocrine control of female reproduction of Lymnaea stagnalis. Exp. Parasitol. 65:91-100.

DeJong-Brink, M, Bergamin-Sassen, M, Solis Soto, M, 2001: Multiple strategies of schistosomes to meet their requirements in the intermediate snail host. Parasitol. 123:129-41.

El- Dafrawy, SM, Sharaf El-din, AT, Bakry, F, Dosouky, AM, 2001: Effect of double infect- 
ion with Schistosoma mansoni and Echinostoma liei on some physiological parameters of Biomphalaria alexandrina. J. Egypt. Soc. Parasitol. 31:433-47.

El-Beshbishia, SN, El-Bardicy, S, Tadros, M, Ayoub, M, Taman, A, 2015: Spotlight on the in vitro effect of artemisininna phthoquine phosphate on Schistosoma mansoni and its snail host Biomphalaria alexandrina. Acta Trop. 141:3745.

El- Sayed, K, El-Dafrawy, S,Sharaf El-Din, A, 1999: Influence of Shistosoma mansoni infection on Biomphalaria alexandrina snails under laboratory condition. Egypt. J. Zool. 33:343-54.

Farahnak, H, Ghobadi, A, Bagheri, F, 2005: Morphology of Biomphalaria glabrata haemocytes and their interaction with miracidium of Shistosoma mansoni. Acta Med. Iranica 43:20911.

Glauert, A, 1974: The high voltage electron microscope in biology. J. Cell. Boil. 63:717-48. Granath, WO, Yashino, TP, 1983: Lysosomal enzymes activities in susceptible and refractory snail groups of Biomphalaria glabrata during the course of infection with Shistosoma mansoni J. Parasit. 69:1018-26.

Helal, EG, El Dafrawy, SM, Mohamed, AH, Abou-El-Nour, BM, Abu Taleb, HM, et al, 2014a: Analysis of circulating heamocytes from Biomphalaria alexandrina following Schistosoma mansoni infection using flow cytometry. Egypt. J. Hosp. Med. 54:41-54.

Helal, EG, El-Dafrawy SM, Mohamed, AH, Abou-El-Nour, BM, Ibrahim, S. 2014b: Ultrastructural study on Biomphalaria alexandrinahaemocytes infected with Schistosoma mansoni in Egypt and its correlation with nitric oxide level. J. Egypt. Soc. Parasitol. 44:113-24.

Henry, M, Pauthedayde, D, El-Badaoui, H, Braut-Boucher, F, Achard-Flleouk, S, et al, 1989: Comparison of the effects of two gypsogeninsaponins towards plant and animal cells in vitro. Pharmazia 44:798-9.

Holmes, JC, Zohar, S. 1990: Pathology and host behavior. In: Parasitism and Host Behavior. (Barnard CJ, Behnke JM. Eds.)". Tylor and Francis.

Kamel, AG, Refaat, SM, El-Dafrawy, SM, Mohamed, AH, Mossalem, SHH, 2006: The effect of Schistosoma mansoni infection on Biomphalaria alexandrina haematocytes at ultrastructure level. Proc. $4^{\text {th }}$ Int. Cong. Biol. Sci. Zool.:219-26.
Lemos, QT, Andrade, ZA, 2001: Sequential histological changes in Biomphalaria glabrata during the course of Schistosoma mansoni infection. Mem Inst Oswaldo Cruz 96: 719-721.

Loker, ES, Bayne, J, 1986: Immunity to trematode larvae in the snail Biomphalaria. In: Immune Mechanisms in Vertebrate Vectors. (Lackie, A.M. Ed). Oxford. University Press, N.Y.

Meuleman, EA, Bayne, CJ, Van Der Knaap, WP, 1987: Immunological aspects of snail-trematode interactions. Prog. Clin. Biol. Res. 233: 113-27.

Mohamed, AH, Sharaf El-Din, AT, Mohamed, AM, Habib, MR, 2011: Tissue responses exhibited by Biomphalaria alexandrina snails from different Egyptian localities following exposure to Schistosoma mansoni miracidia. J. Bact. Parasit. 2:104-9

Mohamed, SH, Saoud, MF, Rivera, ER, Bruce, JI, 1993: Granulocytes and hyalinocytes in Biomphalaria alexandrina resisting infection with the Puerto Rican snail group of Shistosoma mansoni Abst. SRP. Conf. Cairo Egypt Feb. 17: 165-72

Parker, GA, Chubb, JC, Ball, MA, Roberts, GN, 2003: Evolution of complex life cycles in helminth parasites. Nature 425:480-4.

Rizk, MZ, Ahmed, MB, El-Fayoumy HM, Khalil, WKB, Kamel, NN, 2011: Response of two vector snail species to infectivity with compatible and incompatible Schistosoma parasites. European. J. Exper. Biol. 2:206-18

Romeis, B, 1989:MikroskopischeTechnik. Auflage, Urban \&Schwarzenberg, Munchen-WienBaltimore 17:235-6.

Sasaki, Y, Furuta, E, Kirinoki, M,Seo, N, Matsuda, H, 2003: Comparative studies on the internal defense system of schistosome-resistant and -susceptible amphibious snail Oncomelania nosophora: Comparative morphological and functional studies on hemocytes from both snails. Zool. Sci. 20: 1215-9.

Sullivan, JT, Yeung, JT, 2011: Tissue invasion of laboratory-reared Biomphalaria glabrata by a harpacticoid copepod. J. Invert. Pathol.107:15960.

Thompson, SN, 1993: Redirection of host metabolism and effects on parasite nutrition. In: Parasites and Pathogens of Insects, (Beckage, N. E., Thompson, S.N. and Federici, B. A. (Eds.). Academic Press, New York

WHO, 2012: Accelerating work to overcome the global impact of neglected tropical disease:A 
roadmap for implementation. Available from: http://www.who.int/neglected-diseases/ NTD

Zahoor, Z, Davies, AJ, Kirk RS, Rollinson, D, Walker, AJ, 2010: Larval excretory-secretory products from the parasite Schistosoma mansoni modulate HSP70 protein expression in defense cells of its snail host, Biomphalaria glabrata. Cell Stress Chaperones 15: 639-50.

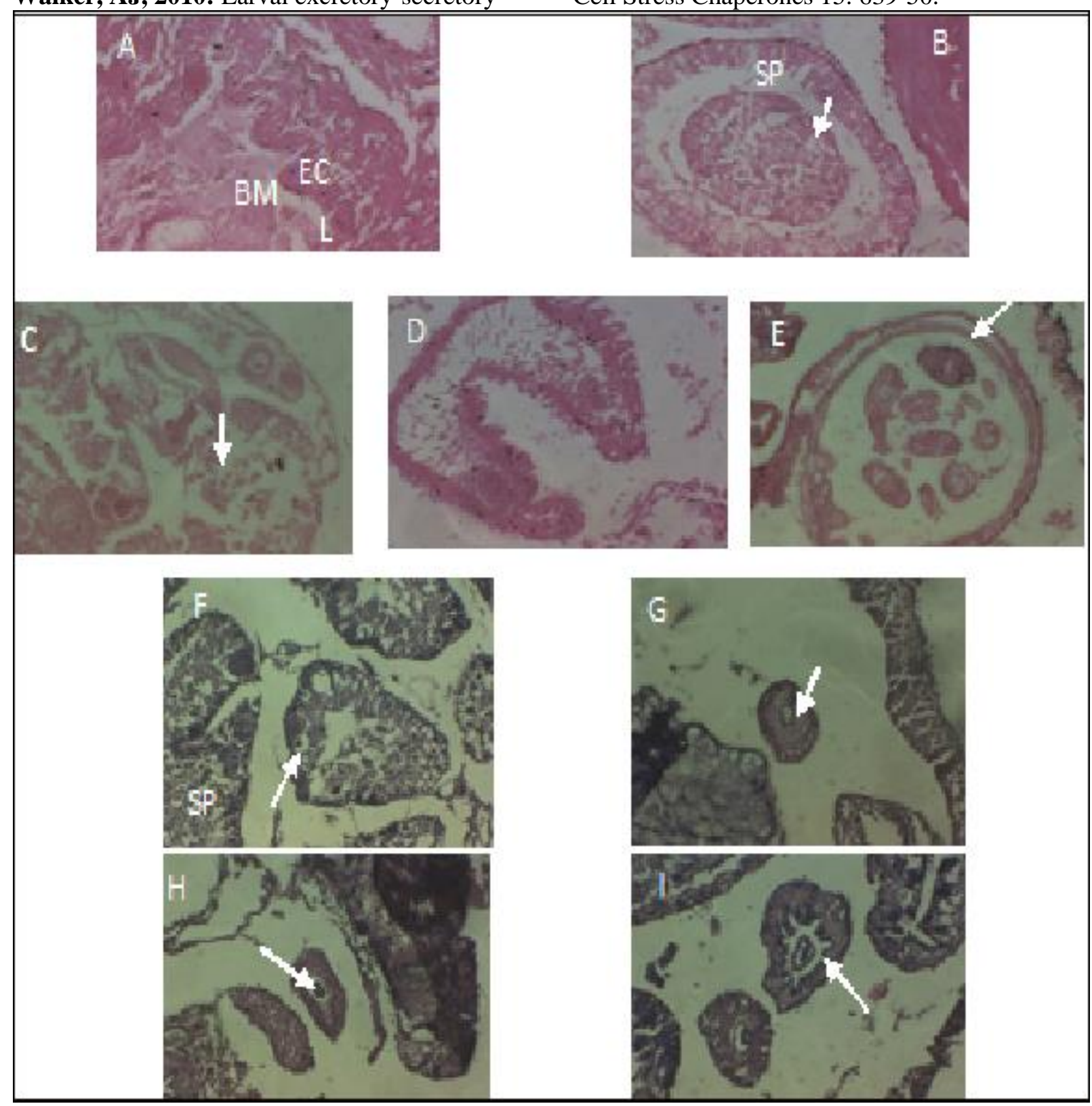

Fig. 1: Histological section in control Biomphalaria alexandrina snails showing (A): Normal structure of digestive gland endothelial cell (Ec,) lumen (L), Basement Membrane (B.M). (B): Developmental stage of spermatocyts(sp) and oocyte (arrow) (40x). In infected Biomphalaria alexandrina snails showing (C): Degenerated oocyte. (D): Degenerated digestive gland. (E): Degenerated spermatocyt (arrow) (40x). In non-infected Biomphalaria alexandrina snails showing (F): Oocytes with mild degenerated ova (arrow) with normal spermatocytes (sp). (G): Degenerated miracidia inside granuloma like structure of concentric layer of fibroblasts with some haemocyts (arrow). (H): Folded miracidia entrapped within snail germ cells (arrow) surrounded by haemocytes. (I): Granuloma- like structure formed in digestive gland (arrow) (40x). 


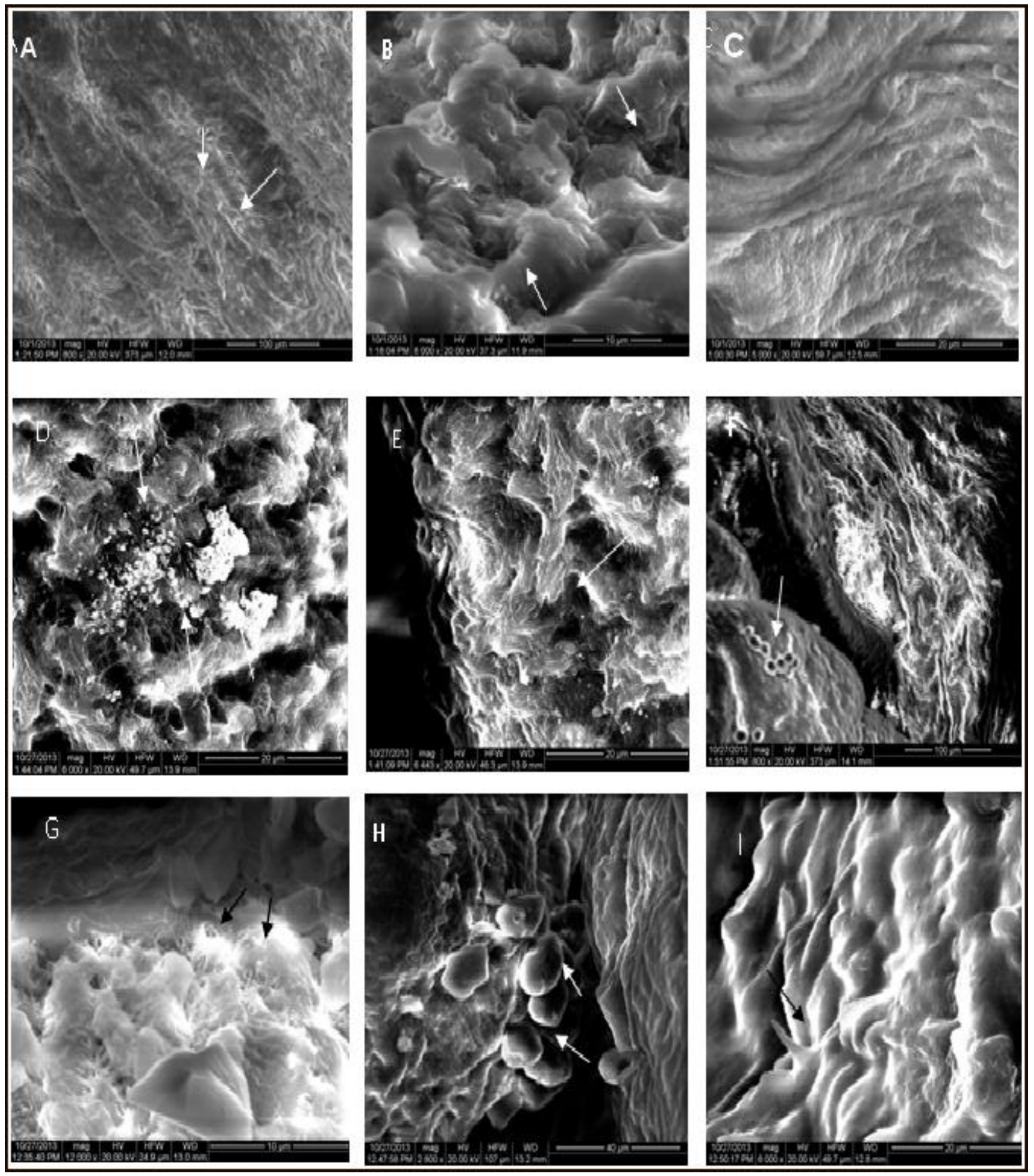

Fig.2: Scanning Electron Microscopy of control Biomphalaria alexandrina snails soft tissue showed densely attached numerous cilia (arrows) (800x A). High magnification showed many folds, and cilia (arrows) (8000x B); Smooth tegumental surface of mantal visceral mass $(5000 x \mathrm{C})$. In infected Biomphalaria alexandrina snails soft tissue showed extensively damaged and fibrosed non-motile cilia (arrows) (6000x D, 6443x E). Exfoliation of tegumental surface, and appearance of subtegumental tissue (arrow) (800x F); In non-infected Biomphalaria alexandrina snails soft tissue showing attached numerous cilia at ventral surface (arrows) (2800x G); Some ballooning of folds start to appear on surface (arrows) (12000x H, 6000x I). 